\title{
Museum as Counterpublic Space: Performing Direct Testimony
}

\begin{abstract}
Utilitarian and socially engaged, Applied Drama is a theatre domain and umbrella concept associated with social sciences, anthropology and cultural studies among other humanistic disciplines. The practice of Applied Drama has played a significant role in developing community-based interventions, contestations and acts of resistance in the public domain, and politically meaningful interactions between artists and audiences to encourage active citizenship. This article discusses the pursuit of Applied Drama from the public sphere perspective and how these specific theatre methodologies are particularly designed to generate counterdiscourses. I will focus on the role of location/place in attributing meaning to the performance piece and illustrate with a study case how museums can be important arenas for democratic public spheres. I will pose that museums are community spaces able to provide opportunities for multiple identities to create representative discourses. I will also demonstrate how immersivity, guided interaction and simultaneous dramaturgy are key factors in generating counterpublics and alternative political discourses.
\end{abstract}

Keywords: Applied Drama, counterpublic, counterdiscourse, museum, Memodrome

Working at the intersection of theatre and social sciences, Applied Drama is a theatre domain "that resonates methodologically and aesthetically with socially engaged art, community-based interventions, education and pedagogy, acts of contestation and resistance in the public domain, cultural struggles or the critical understanding of contemporary political discourse" (Doczi, 2018). Also known as Applied Theatre or Applied Performance, Applied Drama is an umbrella term that connects a multitude of practices and methodologies as varied as
Anca DOCZI LUCHIAN

Babeș-Bolyai University

e-mail: ankadoczi@gmail.com

EKPHRASIS, 1/2021

COUNTERDISCOURSES AND

COUNTERPUBLICS IN CINEMA, ART, MEDIA AND LITERATURE pp. 104-124

DOI: 10.24193/ekphrasis.25.8

Published First Online: June 21, 2021 
Forum Theatre, Invisible Theatre, Reminiscence Theatre, Verbatim Theatre, and Playback Theatre and many more, including the method I have designed, called Memodrome. The craft is therefore established and broadened by a myriad of strategies and disciplines that fall under its framing, from the total audience interventions of Forum Theatre to the improvised acted vignettes of Playback Theatre, and the directly but objectively collated reports of Verbatim Theatre ${ }^{1}$ (Paget, 1987; Hammond and Steward, 2008).

Sheila Preston, one of the most prolific researchers and facilitators in the field, regards contemporary applied drama projects as artistic initiatives whose content is determined by social and political agendas, such as civic renewal, social justice, the promotion of a healthy life and well-being or social inclusion of the socially, culturally and/or economically marginalized communities (Preston, 2016). From a historical perspective, Preston notes a significant shift in the practices of the 70 s and the 80 s, identifying the transition from a clearly politically motivated attitude to a relatively more discreet activist approach in its social and political intentions. This change, Preston believes, marks the need of practitioners for legitimacy, but also the increasing professionalism and expertise of artists in community work. Thus demonstrating the effect and impact on health and well-being, but also in response to the permanent changes of political and social agendas, there was a shift from cultural intervention to a rather instrumental approach (Preston, 2016).

Hellen Nicholson, another prolific researcher in the field, proposes that the terms Applied Drama / Theater became widespread in 1990, being favored by academics, theater practitioners and even politicians to define those dramatic activities that exist mainly outside conventional theatrical institutions and are specifically designed for the benefit of individuals, communities and society (Nicholson, 2005). Judith Ackroyd, professor, author and practitioner, also suggests that, whether we use the term theater or applied drama, the common element is their specific intentionality, the aspiration to improve people's lives and create better societies (Ackroyd, 2007).

The political turmoil of the 21 st century has generated a productive arena for more radical performative creations, thus shaping the way cultural intervention and activism are practiced. The history of Applied Drama is closely related to the practice of cultural activism. As Helen Nicholson suggests, these forms of theatrical expression provide a visible and immediate scene for civic involvement, protest, or political intervention (Nicholson, 2011).

Applied Drama has had an enormous impact on the expansion of performance arts in Western societies and has laid the ground for innovation in the wider theatrical field, while embracing some of the most significant subjects of social and political life. Utilitarian or socially engaged theatre provides new ways to engage audiences, supporting communities to participate in the production of culture and to revisit their own social performances. As Boal suggests through his work, one of the main objectives of his practice is to help people, the "spectators" to become "actors" and take an active role in society. In his view, this is 
achieved by a performance making that enables the shifting of the power paradigm: from the traditional theatre making, where the spectators "delegate their power to the character," to a practice that empowers the "spectator" to assume the role of the protagonist and to challenge the order of the society (Boal, 2000).

With a strong focus on the personal stories of individuals and their collective experiences within the communities, the practice of Applied Drama has played a significant role in developing community-based interventions and socially engaged interactions between artists and audiences that encourage active citizenship (Prentki and Preston, 2009). As Nicholson suggests, emphasising the life and identities of local communities has been a resonant direction of inquiry in the field of Applied Drama, responding to a renewed interest into the ideals and questions of belonging (Applied Drama, 84). Anthropology, cultural studies and many other humanistic disciplines have been absorbed to some extent by Applied Drama, in order to germinate new knowledge about our social life through performance.

Beyond its social and political functions, Applied Drama has spawned the revisiting of the role of arts and the artists in shaping the world: "Applied Drama artists have empowered marginalised voices and peripheral communities to generate critical tools that enable them to shape 21st century thinking” (Doczi, 2018).

\section{The performative space}

One of the elements that sets Applied Drama and socially engaged performance apart from traditional theatre is the use of space and place. Once theatrical performance art came out of the building of theatre, space became a symbolic signifier and a dramatic agent in the construction of the narrative. I find particularly suggestive Nick Kaye's explanation: if one can accept that the meaning of utterances or actions is influenced by their "local position," therefore by their relation to place and the circumstances which they are part of, then a work of art should be regarded in the same way. The theory of semiotics supports that the reading of a work of art implies location-to read a sign implies locating the signifier, to have identified its place in the semiotic system (Kaye, 2000).

I argue that a performance art piece that has exited its traditional site is strongly bound and in a synesthetic relation to its place. Even when location is not intentionally commissioned for a certain art piece, every aspect of it, from the geographical location to the architecture and history, adds to the narrative of the art event. In addition, places or locations are landmarks of the community and the memories tied to them; therefore, their significance within the community will influence the "reading" of the performance.

In Staging the UK, Jen Harvie praises the mnemonic power of place in facilitating the negotiation of meaning. She suggests that site-specific performance is a prodigious 
mechanism to trigger remembrance and community bonding (Harvie, 2005). Fiona Wilkie's survey "Mapping the terrain" shows how site-specific theatre making has not only attracted new audiences through recognising the presence and encouraging the engagement of site inhabitants, but also promoted the space as a living entity. Researching site-specific art, she captures the strategies involved in the creation of such work and demonstrates how performances are influenced by the local community (Wilkie, 2002).

For example, my choice of locations in creating each of the Memodrome performances was determined by the symbolic connotation of their historic and cultural background. Memodrome: Incubator, a story of forced exile, was staged at the Romanian Cultural Centre in London's Manchester Square, a site that holds the most influential archive of the Romanian exile. In addition, the Centre is a cultural hub for Romanians living in London and a place where the community participates in the performance of its culture, to celebrate Romanian traditions and to commemorate the historic struggle for democracy. Memodrome: Home, a story of chosen exile, of living in between and of transgressing cultures, was firstly staged at the Horniman Museum and Gardens in London. The museum houses an eclectic collection of cultural artefacts, speaking of the diversity of cultures that inhabit the city. As my artistic proposal meant placing human subjects as living displays of Romanian culture, their memories serving as cultural artefacts, the museum proved to be a most accommodating home for the performance. In addition, at that time, Horniman Museum was housing a temporary exhibition of Romanian artefacts and the performance took place during the Crossing Borders event, an annual celebration of local communities. The museum's event contributed to the construction of a feeling of belonging for the Romanian community in London and added meaning to my performance.

\section{Public Space and Community. Performing Democracies}

For the purpose of understanding Applied Drama and the making of contemporary performance in the service of communities, a historical perspective of space as location and of public space as the meeting hub of publics can be a useful tool to discuss the relations at work, the paradigms of audiencing and how democracies are being performed.

I find particularly useful Gill Valentine's insight into the concept of public space, while she demonstrates how physical space plays an important role in the constitution of social relations and identities. She argues that, in the late nineteen and at the beginning of the twentieth century, space was something to be investigated, mapped and classified with clear, instrumental and mathematical technologies. After WWII, the focus moved on spatial order and the use of qualitative methods to predict human behaviour into certain spaces. Space 
became, Valentine suggests, "a container of social relations and events" (3). Early 21st century and postmodernism brought an even more elevated sensitivity to the multitude of variations regarding human behaviours and performances into one space, depending on culture, class, agendas, context, experiences and so on. In this direction, Messey suggests that physical space is made up of all the relations performed there, material or immaterial, and, therefore, public space is always in a process of becoming (Messey, 2009). Following the same line of thought, I argue that public space is an entity that collects meaning based on the performances and discourses taking place in it at any given time.

In critical theory, however, public space becomes a discursive arena, a sphere where political discourses are being negotiated. The concept is often viewed through the lenses of Jürgen Habermas's theory and of his supporters or critics. He defines public space as made up of private people gathered together as a public and articulating the needs of society with the state, and a theatre in modern societies where political participation is enacted through the medium of talk (Habermas, 1991). In his view, the public sphere is aimed at mediating between society and the state, by holding the state accountable to society via "publicity." This arena is distinct from the state and it can be critical of the state by creating alternative discursive practices and relations (Habermas, 1991).

Nancy Fraser, Habermas's most ardent critic, argues his theory fails by only addressing the bourgeoise public sphere. She demonstrates how groups based on race, gender and class identities are being excluded from the bourgeois space of deliberation and therefore remain subordinated to this "dominant public." She further suggests that subordination to a dominant public leads to the formation of "subordinated publics" or of "counterpublics," as spaces where alternative identities and interests can be represented. Fraser also poses that Habermas's theory is exclusionary to the level of cultural ethos. She argues that, in stratified societies, marginals develop various cultural styles leading to the formation of informal pressures that separate and disengage these groups even more. These pressures, she notes, are amplified by the political economy of the bourgeois public sphere. In this dominant public sphere, the media where these views are being circulated is privately owned and for profit. Therefore, "subordinated social groups usually lack equal access to the material means of equal participation” (Fraser 64-65).

Later studies also bring into discussion how public spaces-both as locations and as discursive arenas-are vital to the performance of democracies. Public space is therefore imagined to be

accessible, in a material and an abstract sense, to all members of society. The material form of public space must be available, it is thought, in order for people to have the opportunity to participate in democratic processes. The right to protest and demonstrate, to have a "speakers' corner," is considered by these authors as a material and symbolically significant sign of a democratic society. (Barrett 9) 
Melanie Loehwing and Jeff Motter, however, draw attention upon the concept of democracy and its variations in the public space theory. In Publics, Counterpublics, and the Promise of Democracy they suggest that there is little insight into what kind of democracy is being discussed when we discuss about public spaces and publics. They argue that democracy is invoked in all studies on the subject; however, none makes it sufficient clear. The authors propose that Habermas's democracy thrives through the culture of criticalrational debate in the public sphere, while counterpublic studies illustrate democracy as both the site where couterpublics are performed, and the optimal universal level of access to participation. Furthermore, these authors question whether we should understand public sphere as a means for expanded participation into decision making, or as an opportunity to create a democratic culture in which problems can be addressed, discussed and understood differently (Loehwing and Motter, 2009).

Nancy Fraser argues that in hierarchical societies, contestations among a plurality of competing publics need to be supported and accommodated in order to ensure the parity of participation. The focus on the multiplicity of publics articulates the tensions between the counterpublics and a dominant public. She suggests that the existence of a public space where all these publics can perform is a sign of a true democracy because it generates public discourse on different levels (Fraser, 1990).

Encapsulating different methodologies, Applied Drama is tributary to both physical space as a container of publics, their histories and behaviours, and to the public sphere as a platform where political notions can be negotiated and democracies performed. Forum Theatre, for example, needs to be performed at the location of conflict, while Playback Theatre requires its public to be knowledgeable and engaged with the themes discussed. They both imply their audiences to be politically engaged and to contribute to the creation of meaning and effective outcomes.

\section{Publics and Counterpublics}

I also find useful to clarify what the term "public" refers to and Michael Warner's account of it is particularly relevant in this respect. He urges us to note the distinction between "the public" and "a public." "The public" connotes a social totality; it refers to a nation, to a city, the state or any other community, whereas "a public" describes a concrete audience, a gathering of people that are able to witness themselves in a visible space. The sense of totality, in this case, comes from being bounded by a shared space. Warner argues that distinctions between the different senses are very subtle: when the discourse is not addressed to an institutional audience or to a subcultural audience-a profession for example-the audience can see itself more like "the public" rather than "a public" (Warner, 2005). He claims that "a 
public" is organised and self-organised by discourse, and it does not exist outside the particular discourse addressed to it. However, Warner shows that addressees may not be the same with the actual public, and that they are rather imagined addressees, especially with literary texts, advertising, drama, journalism and so on. Nevertheless, all addressees have a social base and a public is defined as the relation between strangers that are bound by territory or by identity, by believes or other forms of memberships that are already organised through independent means or through institutions.

Publics, Warner suggest, independent of institutions, begin with the moment of attention. Therefore, they can be understood in the civil society conceptual frame, having a voluntary and active membership. This conceptual framework allows us to regard publics as platforms of active participation, rather than prescribed participation. Furthermore, it allows us to ascribe agency to them, even in the absence of a concrete manifestation (Warner, 2005).

I would like to note here that Applied Drama publics are particularly targeted groups of people consenting to participate in the creation of alternative discourses and performances of citizenship. A "public" can therefore be, as in Fraser's case, a subordinate group who opposes the dominant one by formulating alternative discourses based on their particular needs and interests (Fraser, 1990). Based on her theory, a public becomes a counterpublic when it responds to exclusions by and from the dominant one. Fraser also explains counterpublics have a dual character: that of "withdrawal and regroupment" (68), which suggests that public space can also be the place where discourses are being created, developed and targeted towards other publics.

Asen suggests that "counterpublics" is a critical term, as it signifies the collective arising in recognition of various exclusions, giving an arena for those alternative discourses and debates that might help at overcoming those exclusions. He adds to Nancy Fraser's theory that counterpublics emerge as a public when the public sphere comes together as a multiplicity, illuminating the different power relations among diverse publics. Asen argues that counterpublic theory is informed by the ability of the multiple public spheres to challenge the power relations and to reveal potentially emancipatory and affirmative practices with the hope that power may be reconfigured (Asen, 2006).

The emancipatory projects of counterpublic spheres are less at risk of promoting an ideal of universality as in Haberman's case. They rather stand for specificity in relation to gender, race, sexuality, ethnicity or other frames of differentiation (Fraser, 1990; Asen, 2006). According to Felski, differentiation in constructs constitute a "partial or counterpublic sphere" (qtd. in Asen 429). In her view, as Asen notes, "[p]artiality enables the formation of a common identity among participants in a counterpublic sphere. This common identity unites participants beyond their individual differences. Participation therefore relies not on an acceptance of a 'clearly delineated theoretical framework, but on a more general sense of commonality in the experience of oppression"” (qtd. in Asen 429). 


\section{Museum as a Public Space}

Jennifer Barrett discusses how newer debates on public space reclaim spaces that are now rediscovered as more significant for communities. She considers political or community spaces which are related to distinct political struggles. From this perspective, a group that comes together in such space may become associated with a particular contestation of the government or a particular economic enterprise, reinforcing the separation from both private and public sphere. She further demonstrates that one of these emerging spaces-and the most significant-is the museum. In her view, the museum constitutes a public space where critical visual discourses are calling for a specific public sphere (Barrett, 2011).

As Jennifer Barrett suggests, claims are being made that museum is not just a public space, but a place where public discourse takes place. With different accounts on the public nature of the museum, symbolic references are being made to imply the relevance of museums in democratic societies. However, the "production of a public sphere involves complex exchanges and negotiations between different forms of communication and practices of 'being in public"' (Barrett 16). The practice of being part of the public in the space of the museum implies recognising the variety of discourses and also being aware of the citizenship strategies that contribute to the formation of a democratic performance, which further demonstrates the democratic nature of the museum (Barrett, 2011).

As an artist living and creating work in the U.K., I came to regard museum as a political arena where memory is collected and displayed strategically to enunciate the "appropriate" history and identity discourse. And this is why, in creating Memodrome: Home, I have chosen Horniman Museum \& Gardens, an anthropological museum specialised in connecting its audience with global cultures.

\section{Creating a new Applied Drama technique}

I have created the concept of Memodrome as a new Applied Drama technique, utilising documentary methods and simultaneous dramaturgy, ${ }^{2}$ curating personal memories and staging performances with direct testimony. In designing the technique, I aimed at exploring how the revisiting of native traditions can empower diasporic "communities to claim their identity through performative means that are already familiar and personal to them" (Doczi, 2018). My practice was conceptually informed by the Romanian tradition of șezătoare and aspired at reconstructing its functions in the form of contemporary performance, by articulating those aspects that are universal to humans, irrespective of their ethnic or racial background: the need to share memories, to tell stories and to unite in the feeling of belonging. The London based Memodrome performances where aimed at contributing to "how we, 
as artists, can facilitate change and empower the communities we live in; to understand how globalisation has given birth to new ways in which communities are performing their cultures and how this trend can envision practical and strong democracies" (Doczi, 2018).

In the following I would like to present my Memodrome: Home performance as a study case to demonstrate how my artistic choices related to location, dramaturgy, participation and audiencing gave birth to an alternative discourse in identifying Romanians and their diasporic experiences as opposed to the dominant discourse present in the U.K. media. I will indicate how the performance actively contributed to the creation of a counterdiscourse with a multiplicity of publics within, and how guided participation allowed members of the audience to negotiate their own political agendas emerging in a model of democracy and active citizenship.

\section{A public narrative of Romanian migration in the U.K.}

The story of Romanian migration in the U.K. has mostly been illustrated in the media and through online social networks. While the Romanian diaspora has intimately nurtured a dual narrative, equally charged with bursts of nationalism and self-hatred (Tradafoiu, 2013), the British press had just one story to tell: barbarian Romanian migrants are "flooding" the country in a quest to "steal British jobs." Probably some of the most intense coverage of the Romanian migration story happened around 2012, with articles dating back to 2006 and showing British companies advertising in Romania for a cheap labour force to build the Olympic sites and an increasing interest from Romanian unskilled workers to search for jobs in construction industries (Boffey, 2006). Another period of high coverage was between 2013 and 2014 when lifting the work restrictions for Romanians took the stage of the British press.

As a Romanian migrant in the U.K. since 2011, I have personally been witness to a negative flow of newscasting (Migration Observatory Report, 2014) that has led to a striking public campaign to denigrate the Romanian diaspora living in Britain (Torre, 2013). A significant part of the mainstream media forecasted a "flood" of Romanian migrants who would invade the U.K. labour market, which in the end did not materialise (Arnett, 2014).

At the same time, migration would become an alarming issue at home as well: in 2014 the Romanian press was publishing reports from the Romanian National Institute of Statistics on the dramatic changes in the country's demographics. It was determined that Romania recorded the most abrupt decline of its population among European countries after Bulgaria: nationally, the population had decreased back to its numbers from the 1966 census (Deak, 2015). While the most significant causes for population decline reported by the National Institute of Statistics were natural ones, such as lower birth rate, high infant mortality rate 
— the highest in Europe — and a high death rate, migration had a dramatic impact. It appears that a huge number of women of childbearing age have opted to leave the country, as one Romanian citizen leaves the country at every five minutes and 27 seconds (Demograf, 2014). It is now thought that every Romanian family has at least one close family member living and working abroad. While official data indicates that Romania has a growing economy, low unemployment status and it is thriving in many aspects, the country is losing 37 people per hour, many of them due to migration (Surd, 2014).

While the most common concern about migration on the Romanian side is related to brain drainage and skilled work force reduction, the portrait of the Romanian migrant seen through the eyes of the British press is illustrated by images of rough sleepers, Roma beggars, male offenders, impoverishment, exploited children and trafficked women.

The official narrative of Romanian migration speaks of exodus, poverty, disillusionment, corruption, political tensions in the European Union, discrimination and criminality. While the social and economic factors that are pushing Romanians out of their country are being largely captured by the mainstream channels of communication, the story of Romanian migration rarely depicts the subjective experiences of living in a diasporic context, and even less frequently the complex web of political and historical struggles in the aftermath of communism. I suggest that these subjective experiences, which are usually hidden to the public eye, are impacting on the identity construction of Romanian migrants and how they are performing citizenship. I also suggest that Romanians' feelings of belonging are influenced by their experience of living under communism, during which time their cultural behaviour was reshaped by repression, fear and suspicion. I therefore claim that exploring individual memories of living in a former communist country can provide meaningful insight into the diasporic living of Romanians in the U.K. Using artistic strategies and applied drama methodologies, I propose an alternative discourse to illustrate matters of Romanian identity.

In this particular performance, Memodrome: Home, I have also incorporated my own lived experience, because of my participation in the life of the Romanian community in the U.K. My attempt to articulate these particular experiences from a variety of viewspoints and political discourses is informed not only by my role as a researcher and artist, but also by my role as a migrant who does not feel represented by the public narrative. In the performance, I open a dialogue based on my assertion that the story of Romanian migration is interlinked on several levels with our communist past, through the historic heritage we relocate and reenact within the diasporic community, symbolising the repository of our shared past.

The artistic approach of Memodrome: Home is not intended to condemn the past or to state a victimised position, but to explore the past in all its complexities while commemorating the memory of pain and celebrating survival and endurance. By doing this, I am also hoping to achieve a model for reconciliation with the self and with the past, within the community, which in turn might result in a stronger construction of the self in a diasporic context. A 
clear and powerful construction of the self, I suggest, enables the individual to contest those public narratives that are derogatory or not representative.

\section{The 'casting'}

Loredana Ivanov, Ana Turcanu, Janos Nagy and Vinicius Les have confirmed their participation in Memodrome: Home as performers. ${ }^{3}$ Selecting the testifiers/performers was central to designing the performance and its narrative outline. The way I envisioned creating the dramatic content depended on their personal stories and on the combination of their objective and subjective identities, which had to lead to the construction of a unitary narrative or rather of a metanarrative. All possible combinations of testimonies that would be extracted by me or the audience would not only have to sit in the frame of the artistic statement, but they would become a unit because of being presented together in one structure.

The selection was a long and systematic process: after creating a performer profile based on age, gender, geographical and cultural origin and ability to speak in front of an audience, I tried to attend as many Romanian events possible: cultural events, community meetings, parties and gatherings, including voting for the Romanian presidency at the Romanian embassy in London.

For almost a year all my social interactions with Romanians were filled with a restless search for suitable performers. My methodology was to carry out informal interviews and field observations without suggesting to anyone that I was targeting them to participate in my project. However, I always described my research and spoke about the aesthetics of the performance I was planning to stage. Mentioning the use of testimony and my interest in personal stories prompted a lot of Romanians to share their experiences with me. However, many showed discomfort at the idea of talking in front of an audience, and concern about taking people out of their comfort zone made me more careful in the selection of the participants. I listened to a wealth of personal stories, narrowing down the field until I identified Loredana, Janos, Ana and Vinicius as suitable to be invited onto the project. When I finally talked to them about the performance and about my proposal, they all accepted with enthusiasm and confidence.

Age played a significant role in the casting of the group, as my interest was in exploring accounts of people who were born around the '80s, during what is now considered the darkest age of Romanian communism. The rationale for this choice was to explore how their own memories, or the intergenerational memories they have been bestowed, have shaped their feelings of belonging and their cultural behaviour.

Moreover, the casting represents a national identity statement in itself, whereby I am proposing a counter-narrative articulated by the exposure of four individuals whom I regard 
as representative of a significant segment of the Romanian population, creating therefore a portrait in contrast to how the general public has been taught to view them.

With consideration to the tensions between how Romanians are identified as Romanians by other people, how Romanians identify themselves among each other and how Romanians really are, I set myself the task of searching for Romanian women and men who could not generally be described as 'economic migrants' and who are not instantly perceived as Romanians based on their physical or behavioural appearance. Therefore, I asked potential performers if their ethnic allegiance had ever been doubted by non-Romanians, if other Romanians had difficulties in identifying them as Romanians and what other categories of ethnic backgrounds they had been connected to. Loredana and Ana mentioned being identified as "possibly eastern European," while Janos and Vinicus reported that people usually find it difficult to place them, and that they would pass as "European" or "Continental." All four reported that people would react with surprise on finding out they are Romanian. In this regard, it is my observation that the majority of Romanians I met from professional or creative backgrounds would have been equally fit for this profile category, as they all experienced surprise from others when mentioning their ethnic background.

Other goals were to attain a gender balance by sourcing an equal number of women and men, though this proved to have its challenges. I had noticed that women were much more willing to share their experience of migration and communism than men, and also more open to their identities and perspectives being publicised through an art project. In addition, I noticed that Romanian women participated in larger numbers at Romanian cultural and social events, while those men that I had met were generally younger or older than my target group. Consequently, I have not been able to capture the life story of a married father who experienced life under communism. However, Vinicius, a father-to-be at the time of the performance, provided a rich insight into paternal roles and how they shaped his position within the family structure. Coming from a male-dominated family environment, his testimony provided a rich source of understanding of traditional and modern family life. Janos provided a different perspective on family life, speaking with generosity about being nurtured by his family into growing up confident and self-aware about his sexuality.

On a geographical level, I managed to cover the central strip of Romania from south to north: Bucharest (the capital, which is located in the central south of Romania), Harghita and Brașov, which are located towards the centre of the country, and Maramureș in the central north. From a cultural perspective, I tried to capture some of the essential cultural influences: Austro-Hungarian and Slavic. However, I failed to represent Oriental and Roma influences because of practical and organisational reasons. The only Roma person I knew who would have met the age criteria is an influential actress who could not match her schedule with ours. This is a loss for the narrative, for the experience offered to the audience and for the present research: according to the Romanian National Institute of Statistics, the Roma 
represent the second largest minority in Romania after Hungarians, and therefore their cultural contribution should be acknowledged in any project based on Romanian national identity. In addition, I believe that because the Roma are a population discriminated against on an international level, as well as in Romania, there is a reasonable expectancy for a more inclusive approach in a research that undertakes to provide the little-heard with voices.

Lastly, the suitable candidates had to be individuals who would feel confident and willing to speak freely about themselves in front of an audience, storytellers who were naturally animated by a sense of living in between and open to taking a journey back in time, as well as willing to commit to the labour of remembering and performing.

\section{The Memodrome: Home performance}

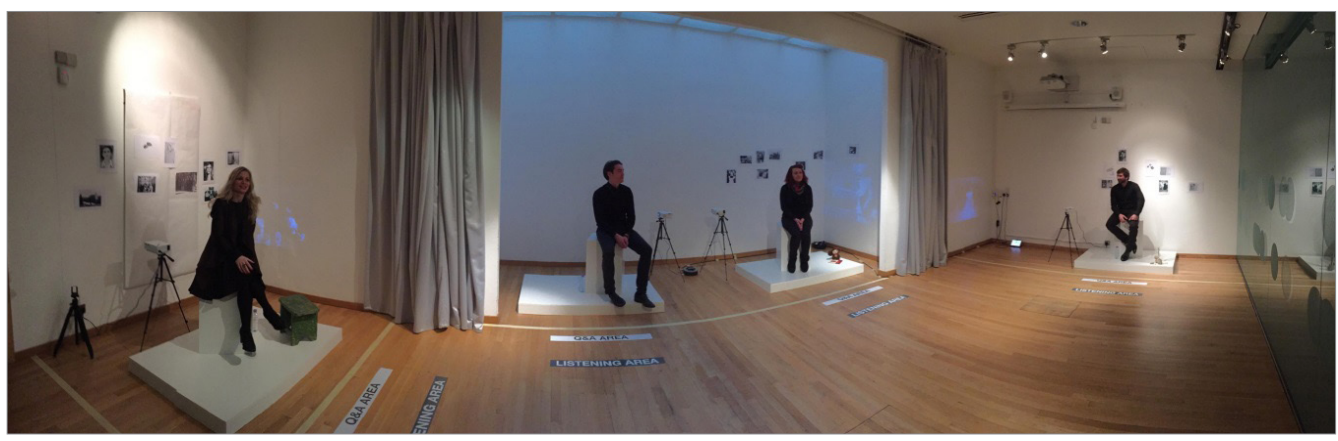

Figure1: Memodrome: Home; the four performers just before the opening, Horniman Museum \& Gardens, London. Photo by Cristian Luchian.

Memodrome: Home was performed at the Horniman Museum and Gardens on $6^{\text {th }}$ of February 2016, within the Crossing Borders festival. Crossing Borders is an annual programme at the Horniman Museum celebrating local communities of refugees and asylum seekers. During the one-day festival local organisations are invited to present creative work that explores their traditions, their culture and their knowledge.

Hosted in the special exhibition room, next to the music gallery, the four-hour performance attracted museum visitors and other guests, some of them Romanians, some of them related by family or friendship to Romanians and some of them interested in the technicalities of the performance. However, most of the audience was formed of unrelated, regular visitors to the museum, who had been the targeted audience in the first instance.

In order to best describe what the experience of the performance is, I will relate it from the audience's point of view: you walk through the Horniman Museum, which covers anthropological themes from nature to human culture. By the time you get to the special 


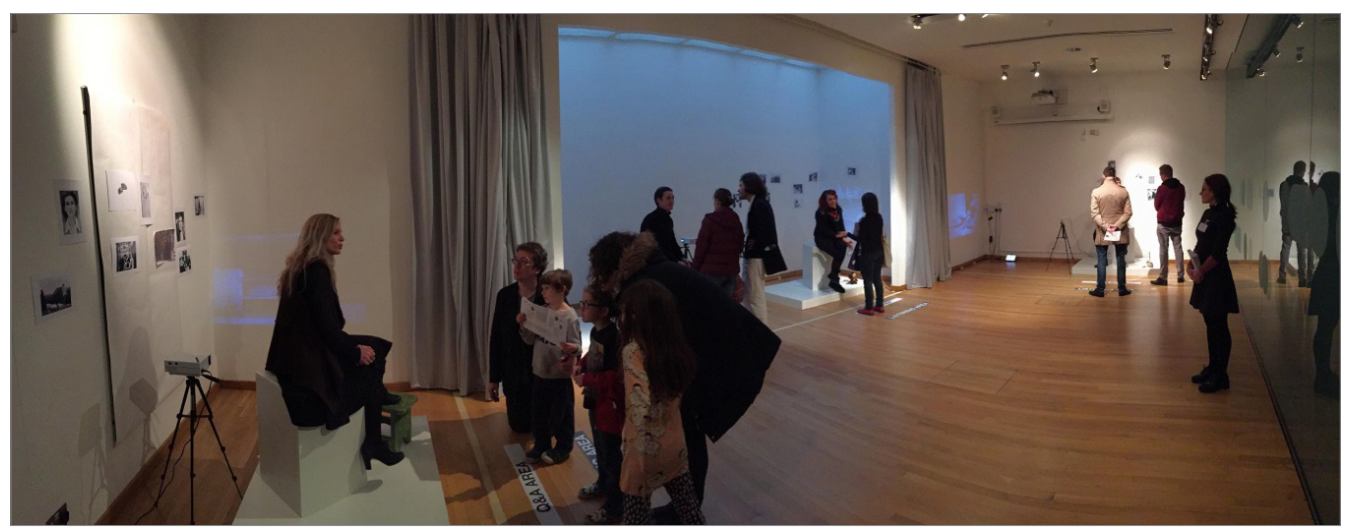

Figure 2: Memodrome: Home at Horniman Museum \& Gardens, London. Photo by: Cristian Luchian.

exhibitions room, you will have visited gardens, natural history galleries, ethnic exhibitions and traditional craft displays, and lastly a music gallery with instruments from different eras and parts of the world. At the end of the glass-framed music exhibition, you enter a room with human subject displays. You receive a written guide telling you are about to enter a performance space, where you will encounter four people. Each of these people will tell you their real stories, while you may watch them, listen to them and even ask them questions, if you approach close enough. From the guide, you learn a simple synopsis of each of the stories and a set of rules establishing how best to explore the exhibition. Once you actually enter the room you see four people, two women and two men, dressed in black, each sitting on a white pedestal, placed on a small white platform. In front of each platform, on the ground, you see two stripes indicating the areas of proximity: the "listening area" and the "Q\&A area." Each of the four individual settings contains one or more objects on the platform next to the performer, a video at the side and printed black and white pictures of them on a white background behind each performer. There is very low background music accompanying the exhibition.

The moment you approach a "listening area" marking, the performer in front of you will start talking to you directly, asking you to share her/his story. If you step forward, approaching the "Q\&A area," you can ask the performer a question, you can start a dialogue, you can share a memory and connect with the performer or with other members of the audience who are present in the same "narrative space." Then, you might want to move and explore another story, but, by the time you reach another performer, her/his story will be at a different stage in the narrative timeline, or you may approach the performer when she or he is responding to somebody's question. You may also turn up in the middle of a conversation and actually listen to a member of audience's story or commentary. You could arrive at the beginning of the performance and have the chance to hear the story from the beginning, or 


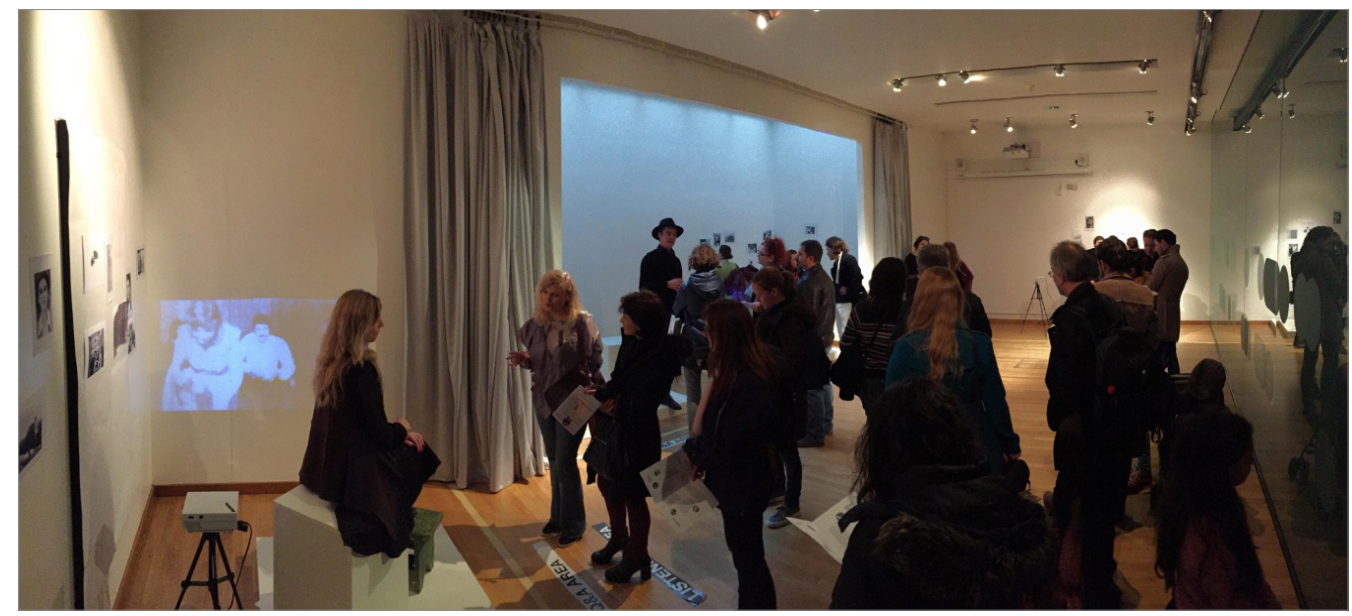

Figure 3: Memodrome: Home at Horniman Museum \& Gardens, London. Photo by: Cristian Luchian.

you could be the fifth member of the audience, at which stage you will listen the story from the point it was at in that moment. You can spend five minutes in front of an individual performer, an hour, or stay until the end of the performance. Some may choose to detach from the spoken story and watch the videos that show images of the performers' native towns, while others might choose to stay in the middle of the room, watching the movement of the other people in the space, catching bits of conversation and stories, looking at body language and experiencing the performance as a conglomerate of voices.

The main element of the performance is the story that you are taking back with you, a story in which you have been one of the characters and that has been staged simultaneously with your own experience, in a performance where you designed the script with all the choices you made, with all the questions you asked in your own order, with all the thoughts you employed to direct the story and with all the memories that arose as part of the interaction.

During the four hours of the performance there were times when each performer gathered one to four members of the audience, times when one performer had a group, while another performer was completely alone, times when there were fifty people in a room where ideal capacity would have been thirty, and so on.

\section{Understanding the audience and looking at public space as a hub of multiple publics}

The publics were formed of Romanians, migrant people of different origins; native English and English-born mixed race visitors attended in balanced proportions. While we advertised the performance to the Romanian community, the museum advertised the event 
to their usual audience. I was surprised, though, by how many children participated and how their presence offered an enhanced sense of performativity and purpose to the storytelling.

In this section I would also like to show the different models of audience participation and varieties of engagement strategies the audience used in interacting with the performance. My main focus during the performance was to capture the different experiences and to take note of people's reactions, time spent in front of each story, and how they alternated their presence in the neutral space, the listening area and the Q\&A area. All these observations have contributed to gaining more control over and confidence in the validity and efficiency of the Memodrome technique.

I posit that the primary driver of audience interaction was the printed guide they received at the entrance together with the information people held in advance from advertising and informal presentations. Interestingly, from what I was able to gather as direct feedback from discussions with the audience during and after the performance, most people's choices seemed to be informed by how the stories summarised in the guide would resonate with their own personal background.

I had the chance to speak before the performance to a young Brazilian man who was fluent in five different languages, including English. I showed him the guide and I explained in some detail about the performance and what I expected from the audience. He confessed he had never been to an immersive performance before or to one that would require his participation. He declared that he couldn't imagine in advance how he would interact during the performance, but he had a clear plan in regards to the narrative itinerary: "I will start with Loredana's story because it seems more simple in terms of the tensions within her identity and maybe continue with Vincius' for the same reason. I then want to hear Janos' story because he brings into discussion two levels of tension: being gay in a former communist country and being both Hungarian and Romanian. And I will finish with Ana's story because it is the closest to my heart. I also feel that I am different in every language that I speak.” During the performance, I noticed him doing exactly what he had suggested: he followed an itinerary that he planned in advance, which indicated to me that he took advantage of his freedom to curate his own experience.

A mixed couple formed of a Romanian woman and a European man (I did not register his exact origin) took a break after spending almost two hours with Janos. They disclosed that their initial plan was to watch all the four performers, but while listening to Janos' story they realised how his experience provided an insightful reference to their own struggle to adapt in a different culture. They resonated on an emotional and intellectual level with his story to such an extent that they needed a time outside the performance space to break the connection with one story before moving to the next one. In their case, the initial plan was impacted by the experience itself and they embraced the unknown.

A Colombian woman spent significant time listening to Ana's story. At one point, she stepped back and seemed to wait until another member of the audience finished his 
conversation with her. I took advantage of that moment to ask about her interaction choices. She disclosed she was not waiting; she was "eavesdropping" on Ana's story. She mentioned that she became interested in Ana's story by reading in the guide that she was born in the former Soviet Union, which instantly made her think of the violence in her own country.

Some of the people I spoke to prior to the performance about the "proximity levels" and the "rules of engagement" felt that I was impairing the democratic flux of interaction or that I was limiting the audience's experience by creating artificial borders. I challenged these opinions by explaining that the "proximity levels" were aimed at creating a material barrier between the performer and the audience, as a visual and abstract acknowledgement of a migrant's experience. In order to promote an emphatic relationship between the testifier and the witness, I have tried to create a "border crossing" experience, memories and personal testimony traversing the divide from the migrant testifier into the symbolic place of the "local" audience. Moreover, the "proximity levels" were meant to render more concrete the emotional and intellectual struggles of someone who steps outside their natural space and enters the unknown or only partially familiar space of a different country or culture.

However, I would like to suggest that what was initially an artistic choice for Memodrome: Home became a programmatic endeavour for the Memodrome technique through the discovery that by visually marking the proximity levels, we achieved an equilibrated power position between testifier and witness.

One young English man from the audience, who planned to challenge the concept of borders, realised that it was exactly the existence of the borders that inspired him to cross them in order to feed his curiosity about Vinicius' story and predicated his awareness of the differences that make the interaction with people from other cultures so fascinating and instructive.

A theatre practitioner to whom I spoke in advance about the setting of the performance confessed that he expected he would feel discontented about the platforms and the individual spatial delimitations of the performers because of the separation from their audience this might cause. The first impression he got on entering the exhibition room was that the four individual spaces would feel like cages for the performers. However, his actual performance experience was that the limitation of the real space had actually opened an unlimited theoretical space of exploration and connection with the performers.

To conclude, the rules of engagement may have had less influence than expected on how people actually chose to engage with the performers, while the stories were a significant determining factor in the choices people made from the beginning to the end of the performance; however, the rules definitely impacted on their rational and intellectual experiences. When thinking of the overall performance, people I spoke to generally felt the engagement framework significantly enhanced their experience.

In order to provide a more clear insight into how the audience interacted with Memodrome: Home I will classify the public into several categories based on my observations: 
The Interviewer Audience, The Witness Audience, The Testifier Audience, The Experience Audience and The Non Audience.

The Interviewer Audience was composed of a significant number of visitors and the attending children. To my surprise, a lot of the audience members would read the guide and then walk straight into the $\mathrm{Q} \& \mathrm{~A}$ area, where they would ask precise questions related to the short abstract presented in the guide. Most of their questions aimed to explore the experience of Romanians as migrants into the U.K. or gather referential information about past and present Romania. In addition, some young people in the audience stayed outside the proximity levels and took notes without interacting with the stories. The majority of children had been advised by their parents to go to the $\mathrm{Q} \& \mathrm{~A}$ area and to ask questions about the history of Romania. Some of them took the opportunity to ask "What is Romania?" or "What are you going to be when you grow old?".

The Witness Audience formed the majority of the audience. They tended to allocate enough time for all the stories and they spent most of their time in the "listening area." They would ask questions to find out more insightful details specifically about the memories shared with them and they would prompt the narrative by commenting on the pictures and the videos behind the performer. In addition, they discussed the emotional charge of the experience and related to me how they had been impressed by the stories.

A friend of mine repeatedly spoke to me after the performance about Janos' grandmother. She described in rich detail the character of this woman, based on the story she heard from Janos, but she continued to imagine outside the story framework how Janos' grandmother's life must have been. I suggested that some audience members similarly continued to "work" on the narratives outside the performance, filling in different possible scenarios, prolonging the life of the performance after the actual time of its material existence.

The Testifier Audience was formed of a small number of audience members. I noticed some people, mostly Romanians, migrating several times from the listening area to the Q\&A area, partly ignoring the proximity levels. They would "recognise" the stories and would share their own memories with the performer or the other members of the audience. One middle-aged Romanian woman told me she "knew those stories very well” and she "didn't need to ask any question." However, she confessed that she was grateful to the performance for "showing her community's stories to other people." The testifier audience, I would argue, was formed of people who "recognised" the memories, who had been part of those community memories as somebody who had experienced the same past and who was able to share a similar experience. The testifier audience felt, therefore, that their voice was heard through our performers' stories. Another Romanian woman told me, "I was feeling ashamed I am Romanian, but your performance made me feel proud; I am leaving with a sense of acquired dignity."

The Experience Audience was formed of a smaller number of people. They would arrive in the performance space and they would stay outside the proximity levels, trying to observe and understand what the experience was about. They would listen to several voices at the same 
time and watch the dynamics of the rest of the audience from an external position. Some people sat on the ground or rested along the empty wall of the room without interacting, avoiding people's glances, sometimes even with their eyes closed. A drama teacher confessed he had brought his students and encouraged them to interact with the stories, but he preferred to distance himself in order to observe how different migrant people interact with each other. Somebody else expressed her interest in the body language being used and thought the four performers all together made an "interesting visual installation."

The Non Audience were people who arrived unintentionally and who refused to take a guide. They entered, looked around, and left the space. I heard disappointed voices saying, "Oh, this is a performance, not an exhibition," or a disappointed child saying to his father: "But father, this is not a real performance," as the father tried to explain that there are different ways of making a performance.

Looking at the audience's interaction with Memodrome: Home informed my under-standing and learning of how a medium such as an immersive installation based on memory work can provide several strategies to engage with various audiences. For example, most of the Interviewer Audience interacted with Loredana's and Vinicius' stories, which provided a more discursive and accessible proposal to start with. The most significant number of the Witness Audience interacted with Janos' and Ana's stories, whose tensions offered a more emotionally charged interaction. The Testifier Audience responded to the share of a "common" past, while the Experience Audience may have been more interested in the technicalities of the work and in the formal representation of the narratives. Therefore, I would argue that the foundation of achieving an engaged and committed audience interaction is based on the collaboration between the substance of the stories presented and the spectating scheme.

While I am unable to analyse the impact of Memodrome: Home on people's beliefs about Romanians, due to the limits of distribution and feedback collection in such an experiment, I am confident in saying that there is an audience for practices such as Memodrome. Most of the people I talked to after or during the performance showed obvious interest in and appreciation for being able to interact with testifiers of real and authentic stories. Some of them had been impressed by the generosity and brave spirit of the performers, who offered themselves openly and unrestrictedly to the audience. I myself had also noted the sense of excitement generated by the authenticity of the stories, and was satisfied to discover how unmediated testimony performed by the holders of the experiences/memories had animated people's curiosity and interest. In addition, all four performers confessed that this was one of the most self-exploratory and self-instructive experiences of their lives.

Acknowledgement: This paper was written with financial support from the POCU/380/6/13/124146 project "Quality, Innovative and Relevant Doctoral and Postdoctoral Research for the Labor Market”, co-financed by the European Social Fund through the Operational Program Human Capital 2014-2020. 


\section{End Notes}

1. Verbatim Theatre is a domain of theatrical activities using testimonies and the exact words of people as its source and it is enacted by actors; it is a form of documentary theatre.

2. Simultaneous dramaturgy is a term we usually refer to when we discuss and practice Forum Theatre, also known as Theatre of the Oppressed, an applied drama technique invented by Brazilian theatre director Augusto Boal. The Forum Theatre technique implies that new dramatic text is created by the audience during the performance.

3. The most important aspect of the Memodrome technique is that performers are not actors or people trained to perform. Their presence on the stage is determined by their personal stories.

\section{Works Cited}

ACKROYD, Judith. “Applied theatre: an exclusionary discourse?”. Applied Theatre Researcher, no. 8, 2007, pp. 1-9.

ARNETT, George. "Flood of Bulgarian and Romanian Migrant Workers Fails to Materialise." The Guardian, Guardian News and Media, 14 May 2014, www.theguardian.com/news/ datablog/2014/may/14/flood-bulgarian-romanian-migrant-workers-fails-to-materialise. Accessed November 1, 2016.

ASEN, Robert. "Seeking the 'Counter' in Counterpublics.” Communication Theory, no. 10(4), 2006, pp. 424-46.

BARRETT, Jennifer. Museums and the Public Sphere. Wiley-Blackwell, 2012.

BOAL, Augusto. Theatre of the Oppressed. 3rd ed. London: Pluto Press, 2000.

BOFFEY, Daniel. “20,000 Romanians Sign up to Build London’s Olympics.” Daily Mail Online, Associated Newspapers, 20 Aug. 2006, www.dailymail.co.uk/news/article-401417/20-000Romanians-sign-build-Londons-Olympics.html. Accessed November 1, 2016.

"Bulgarians and Romanians in the British National Press." Migration Observatory, University of Oxford, 18 Aug. 2014, migrationobservatory.ox.ac.uk/resources/reports/bulgarians-romaniansin-press/. Accessed November 1, 2016.

DEAK, Antonia. “Anunț Alarmant al INS: populaţia României a ajuns la nivelul anului 1966.” România Liberă, 10 Dec. 2015, www.romanialibera.ro/actualitate/fapt-divers/ins--populatiarezidenta-a-romaniei--la-nivelul-anului-1966-401860. Accessed November 1, 2016.

DOCZI LUCHIAN, Anca. "What is Applied Drama." Immersive Theatre. Accessed May 25, 2021 : https://immersivetheatre.com/centre-for-applied-drama/.

FRASER, Nancy. Rethinking the Public Sphere: A Contribution to the Critique of Actually Existing Democracy.” Social Text, no. 25/26, 1990, pp. 56-80. DOI: https://doi.org/10.2307/466240.

HABERMAS, Jürgen. The Structural Transformation of the Public Sphere, translated by Thomas Burger \& Frederick Lawrence. MIT Press, 1991.

HAMMOND, Will and Dan Steward (eds.). Verbatim, Verbatim: Techniques in Contemporary Documentary Theatre. 1st ed. London: Oberon, 2008. 
HARVIE, Jen. Staging the UK. Manchester University Press, 2005.

KAYE, Nick. Site-specific art. 1st ed. London: Routledge, 2000.

LOEHWING, Melanie and Jeff Motter. "Publics, Counterpublics, and the Promise of Democracy." Philosophy and Rhetoric, vol. 42, no. 3, 2009, pp. 220-241. DOI:10.1353/par.0.0037.

MASSEY, Doreen. "Concepts of space and power in theory and in political practice." Doc. Anàl. Geogr., no. 55, 2009, pp. 15-26.

NICHOLSON, Helen. Applied Drama: The Gift of Theatre. 1st ed. Palgrave Macmillan, 2005.

---. Theatre, Education and Performance. 1st ed. Palgrave Macmillan, 2011.

PAGET, Derek. “Verbatim Theatre': Oral History and Documentary Techniques," in New Theatre Quarterly, Vol. 3(12), pp. 317-33, 1987.

“Populația României la 1 ianuarie 2014.” Demograf, 23 Dec. 2014, demograffiti.wordpress. com/2014/02/24/populatia-romaniei-la-1-ianuarie-2014/. Accessed November 1, 2016.

PRENTKI, Tim and Sheila Preston. The Applied Theatre Reader. 1st ed. London: Routledge, 2009.

PRESTON, Sheila. Applied Theatre: Facilitation: Pedagogies, Practices, Resilience. Bloomsbury Academic, 2016.

SURD, Vasile et al. "Major Demographic Changes in the Dynamic and Structure of the Romanian Population after the Fall of the Communism.” Zbornik Matice Srpske Za Drustvene Nauke, no. 148, 2014, pp. 803-811. DOI: 10.2298/zmsdn1448803s.

TORRE, Andreea Raluca. Migrant Lives. A Comparative Study of Work, Family and Belonging among Low-Wage Romanian Migrant Workers in Rome and London. PhD thesis. The London School of Economics and Political Science (LSE), 2013. http://etheses.lse.ac.uk/693/. Accessed November 1, 2016.

TRANDAFOIU, Ruxandra. Diaspora Online: Identity Politics and Romanian Migrants. 1st ed. New York: Berghahn Books, 2013.

VALENTINE, Gill. Public Space and the culture of Childhood. Routledge, 2016.

WARNER, Michael. Publics and Counterpublics. Zone Books, 2005.

WILKIE, Fiona. "Mapping the Terrain: a Survey of Site-Specific Performance in Britain.” New Theatre Quarterly, vol. 18, no. 2, 2002, pp. 140-160. DOI: 10.1017/s0266464x02000234. 